\title{
Stillness in Four Movements
}

ALDEN HENDERSON

May 8, 2017 
Special thanks to the dancers who committed to a long and arduous rehearsal process: Beth Bowen, Rose Kotopka, and Alyssa Peter.

\section{THE \\ BOLLER \\ REVIEW}




\section{INTRODUCTION}

Stillness in Four Movements, a dance performance culminating from a year-long research process, investigates conceptions of stillness as movement in a manner similar to that of John Cage, as he explored silence in music, or Mark Rothko, as he explored the concept of nothingness in the visual arts. In my research, I found that stillness is solely a perceived notion because stillness is impossible; humans have hearts that are always beating, cells that are always decomposing, and atoms that are constantly moving. Thus, the question became, How can one, through dance, engage with the notion of stillness as choreographic material?

Stillness digs into this question through four different sections that address separate aspects of my research. The first of these sections features the dancers performing swift movement about a stationary audiencethe contrast amplifying the audience's somatic experience of stillness. The second section includes stationary dancers amidst an audience that is allowed to move among them. In this way, the dancers act as a true installation, welcome to be the subjects of the audience's gaze. The third section is a responsive section in which the dancers randomly choose an audience member and use the audience member's moments of stillness and movement to activate the dancer's choreographic score. This section integrates the experience of stillness and movement and intends to bring greater awareness to this binary. The dancers also match the scale of the movements of these audience members in order to create variation of scale in their own choreographic score. The fourth section of the work, by repeating a short phrase of movement for twenty-four minutes, examines the various perceptions of time for both dancers and audience.

My initial investigation of stillness began in my Junior Choreography project in which I, curious about how concepts of silence, as applied in Cage's composition, might apply concepts of stillness in choreography. Thus, I began to create a work that explored my experience of silence as applied to choreographic structure. From the beginning of my investment with the subject, I have seen silence and stillness as intertwining ideas because the two have a causal relationship: movement produces sound, and perceived sound produces movement. As I noted earlier, however, there is no true silence or stillness-our bodies are always decaying, atoms always vibrating, so what we see as still is purely perceptual. Because perception is inherently subjective, I began to wonder what the human biases toward silence $\sim$ stillness ${ }^{1}$ are. What does silence stillness communicate? How can the communications and biases found be used to engage an audience in my choreographic research?

\section{TEXTUAL RESEARCH}

In order to establish an understanding of silence stillness and the connotative values they hold, engaging with a multi-contextual view of the silence $\sim$ stillness phenomenon that synthesizes the research of several fields becomes necessary. Examining the work of Joseph Jordania (evolutionary musicology), Natalie Kosoi (visual arts), Kyle Gann (music composition), and Marina Abramovic (performance art), the idea that silence stillness contains within it concepts of mortality and transcendence of self becomes manifest, positing an ontology of silence stillness based in paradox.

Silence is often an uncomfortable state for human beings, so uncomfortable that, in fact, some argue that it conjures feelings of danger in its perceiver. Analyzing the concept of silence as danger through an evolutionary lens, Joseph Jordania—ethnomusicologist and evolutionary musicologist—writes in his "Times to Fight and Times to Relax: Singing and Humming at the Beginnings of Human Evolutionary History" that humans, prior to the formation of language, were like birds in that they communicated via different tones of humming and singing. Among singing species, silence correlates with danger. For instance, when a bird comes to the ground, it stops singing. The bird knows it is no longer in the safety of the trees, so all songs cease in order to avoid predators. The same instinct was present in early hominids when threatened by a predator, and Jordania argues that some of this evolutionary unease in silence remains with us today (Jordania 272-277). The notion that silence signals danger is demonstrated through the seeming human need for sound in order to relax via elevator music or lullabies and might account for the discomfort some audience members may express when experiencing dance in silence.

${ }^{1}$ utilize the tilde to reduce the idea that silence and stillness are separate. Rather than using a back slash or hyphen, which might convey a division between the two concepts, l employ the use of the tilde to link the two. 
Similarly, Natalie Kosoi, in her "Nothingness Made Visible: The Case of Rothko's Paintings," contends that confrontation with nothingness (an extension of the silence stillness phenomenon that relates to space rather than movement or sound) communicates notions of death. Mark Rothko was a famed 20th century painter who is known, in part, for his multiforms: paintings of differently-colored rectangles adjacent to one another. Kosoi suggests that Jean-Francois Lyotard-philosopher and literary theorist-discusses the concept of nothingness in terms of sublimity in his analysis of Rothko paintings and that he "relates the sublime to the horror that nothing will happen and the relief that it is happening" (Kosoi 26). Kosoi, however, disagrees with Lyotard on the notion that relief can befound within Rothko's paintings, and instead argues that the nothinness presented in Rothko's paintings "leav[es] us with only ourselves and our being, which is being-toward-death" (Kosoi 27). Being-toward-death alludes to the fact that "we are born to die" (Kosoi 30), and no matter how we might try to escape this notion, mortality embeds itself in our being and our understanding of nothingness.

Kosoi and Jordania's accounts share a common theme: relating nothingness to mortality. He argues that in Jordania's writing, when in silence, humans are reminded of a fatal danger looming nearby, an idea connecting silence to human conception of our own frailty and impending death. Likewise, Kosoi speaks of the notion that when all other distractions are removed and humans are left with nothingness (as in Rothko's paintings), we are left with our own "being-toward-death" (Kosoi 27), thus linking silence stillness nothingness with the same apprehension of death. In viewing stillness, this apprehension of death mustthen realize itself fully because cessation of bodily movement yields what humans perceive to be total stillness: the corpse in the casket. But is the morbid fate of all humans the sole subject of stillness's communication?

In contrast to Kosoi and Jordania's argument that silence nothingness $\sim$ stillness creates a sense of mortality, Kyle Gann, music composer, suggests in his No Such Thing as Silence: John Cage's 4'33" that through experiencing silence, people are able to transcend themselves and reach an altered state of consciousness. Cage's 4'33" is a four-and-a-half minute composition in which the pianist sits at the bench, adjusts the lid covering the keys a few times, turns a page or two as he or she reads the next notes, and receives applause-no audible noise is made as he or she performs the composition. For many in the audience, the initial performance of the composition was "a kind of artistic prayer, a Zen performance theater that [...] allowed one to hear the world anew" (Gann 11). In likening the audience's experience of the performance to a prayer, Gann insinuates that in the space afforded through silence, audience members are able to transcend into and new layer of consciousness. Additionally, he notes that the performance "transpose[s itself] onto the audience members" (Gann 19), indicating that this heightening of consciousness cannot be achieved without audience members willingly taking the initiative to engage with the work in such a way that is conducive to fulfilling the aforementioned state.

Also within the postmodern artist circle with Cage is Marina Abramovic, a renowned performance artist, who contends that nothingness allows for humans to forge connections with one another more aptly than under normal performance circumstances. Abramovic premiered a performance in spring of 2014 entitled 512 Hours in which she set up a space at the Serpentine Gallery in London for people to come and explore the experience of nothingness. Audience members took a tour of the exhibit wearing blindfolds or sound-cancelling headphones in order for the performance to be an immersive, six-hour experience of contrived nothingness. In a subsequent interview with Intelligence Squared titled "Marina Abramovic on art, performance, time and nothingness," an audience member's comment that she had felt a healing in herself in attending the exhibit met the reply from Abramovic that she herself felt "an unbelievable opening of her heart to [...] total strangers" (Abramovic, "on art, performance, time and nothingness"). Abramovic's account of her experience of her own work indicates that the dissolution of distractions such as cell phones or the internet granted her the ability to connect with other people with an equal dissolution of the barriers she usually holds when addressing "total strangers."

In their research, Abramovic and Gann present information that directly contradicts the nihilistic notions that nothingness brings us humans to confront our own mortality, arguing instead that nothingness offers the possibility of an opening of the self to the world and its inhabitants. Silence $\sim$ stillness $\sim$ nothingness thus becomes a mode by which people may transcend the individual life cycle of life/death and perhaps expand their consciousness to include people around them as well as entertain questions such as life's meaning. 
While the contradiction between silence $\sim$ stillness nothingness as a reflection of mortality and existential nihilism and silence $\sim$ stillness $\sim$ nothingess as an expansion of consciousness and transcendent connectivity to the world may suggest that no meaning lies within silence, my dance utilizes this paradox to provide meaning in itself. I postulate that silence stillness nothingness contains within it the concepts of human fate as well as transcendence of self independently of human perception. In this manner, silence stillness nothingness operates as a mirror in which we might see ourselves, the world behind us, or any array of things based on our perceptions. Despite our inability to perceive everything reflected in the mirror at once, the mirror reflects the things unseen all the same. Thus, a meaning of silence comprises itself of the aforementioned paradoxes, but when presenting silence stillness nothingness, the nothingness "transpose[s] the performance on to the audience members" (Gann 19), leaving the interpretation of the paradox to its perceiver.

With a working conception of what silence stillness nothingness communicates to humans, the defining of silence $\sim$ stillness $\sim$ nothingness as a tangible occurrence becomes an essential element in understanding the phenomenon. In Margulis's and Lyotard's work, repetition and resolution of suspense emerge as factors of the concept of silence stillness nothingness, contrary to the common tendency to discuss the occurrence through negation.

A fast and simple way of defining silence is via negation, or defining silence by saying what it is not-for instance: silence is the absence of sound. As discussed earlier, however, a complete silence or stillness remains impossible because all the matter that is not cooled to zero degrees Kelvin remains in some degree of motion, and, therefore, produces noise. Even nothingness fails to be completely abject of thing-ness because, in the quantum model of a vacuum, the vacuum is filled with virtual particles that interact with actual particles that move through the vacuum, so nothingness fails to be fully void of all else. Troubling this issue further, definition via negation is a reduction of silence $\sim$ stillness $\sim$ nothingness to an emptiness when the communicative value of these concepts can billow into wonderful paradoxes, rich with information.

The research put forth by Elizabeth Margulis, director of the Music Cognition Lab at the University of Arkansas, in her article "Silences in Music Are Musical Not Silent: An Exploratory Study of Context Effects on the Experiences of Musical Pauses" suggests that silence is a result of expectation. She and her fellow researchers find that participants in the case study subconsciously "create anticipation for phrase boundaries, [and...] that the psychological endpoint of phrases may be at the beginning of the final, closing pitch, rather than the pitch's end" (Margulis 488). Essentially, Margulis suggests that the tests performed revealed that participants predictedbased on past experience-what was to happen next, identifying the beginning of an end note to be the end of a musical phrase, rather than the actual end of the musical phrase (Margulis).

Humans, in their desire to find pattern, attempt to make logical sense of whatever is in front of them. So, when a long, sustained note is played, it eventually becomes a musical rest to its perceiver; the same is true of a repeated note at the same pitch and without temporal variance. An idea emerges from Margulis' music research article that suggests that silence [like stillness] is, in part, perceptual, an idea demonstrated through the fact that audience members predicted differently the end note based on previously shown patterns. If the music was more legato moving into the final note, the audience members were more apt to predict the end as well as feel relaxed in the end than when anticipation was building in the notes preceding the end (Margulis).

Similarly, Jean-Francois Lyotard argues a perceiver experiences resolution of qualms once he or she no longer expects something other than nothingness from nothingness, instead expecting continuous nothingness. According to Kosoi's interpretation of Lyotard's ideas of sublimity, a "relief that [nothingness] is happening" (Kosoi 26) permeates our experience of nothingness after we overcome "the horror that nothing will happen." Thus, deliverance from the suspense that nothing at all might happen provides closure to the perceiver of the sublime, allowing him or her to experience "suspense, [a] lessening of a threat or danger, [that] provokes a kind of pleasure [... in] relief" (Lyotard 11) in the repeated nothingness of Rothko's painting. Drawing from Margulis' research, the idea that nothingness repeats itself in sublime art until it registers as a conclusion to the work of art (just as 
repeated notes in music fade into a perceived silence) provides a framework by which to comprehend the erasure of the initial horror that nothing might happen: eventually, the repetition of nothingness fades from perception to become a sensation of relief, or as with some members of Cage's audience, an "artistic prayer, a Zen performance theater that [...] allowed one to hear the world anew" (Gann 11).

While definition via negation provides a convenient and simple definition of silence stillness nothingness, Margulis and Lyotard assert that repetition is a key constituent of the phenomenon of silence $\sim$ stillness nothingness. According to Margulis, people perceive sound and silence based on expectation. Thus, when a note is repeated or sustained for a long duration, it fades from memory and acts as a sort of silence. Lyotard's theories can augment Margulis's experimental data with conceptual research on nothingness in two-dimensional artwork by acknowledging that the initial moments of experiencing a work of art that presents some form of nothingness can be shocking. Eventually, however, the nothingness presented becomes less suspenseful because the viewer continues to observe its repeated nothingness until its nothingness registers simply as what the artwork is and the shock value fades from conscious thought.

Thus, from the works of Gann, Kosoi, Jordania, and Abramovic, one concludes that a paradox exists at the nexus of human perception of silence $\sim$ stillness nothingness in that seeming absence of something can relate that human life is solely working toward demise or, with a perceptual shift, can provide humans with the means to transcend the self and enter into a collective consciousness. This paradox illustrates a complex notion of what silence affords mankind, even if humans cannot perceive the totality of the paradox at once. In terms of defining silence as an occurrence in nature, the theorization and research done by Margulis and Lyotard suggests that silence $\sim$ stillness $\sim$ nothingness might precisely be defined as a predictable repetition that escapes its perceiver's conscious thought.

\section{STUDIO RESEARCH}

In the fall, I was prepared to apply my textual research in studio practice. In the first rehearsal with the dancers, I asked the dancers to move across the floor as slowly as possible for one hour. This improvisation score stems from a score developed by Barbara Dilley, one of the innovators of postmodern dance, and taught in a workshop here at TCU. The three cast members in my work and myself had the same experience within the structure: the first few minutes feel agonizing, but as time passes, the slowness soothes the mind-body into a meditative state, and time passes more quickly than we perceive. Each dancer professed that the time spent in the score felt like no more than twenty minutes. My sample size is not large enough to deduce a proper conclusion from this experience, but what is fascinating is that our experiences aligned with Lyotard'stheory of how humans interact with nothingness: "the sublime horror that nothing will happen and the relief that it is happening" (Kosoi 26). As a viewer, however, Dilley's score failed to invoke in me a sense of 'stillness' that I sought choreographically, so we moved on to the next score and kept the Dilley score as a centering exercise in our rehearsal practice.

Over the following months, the cast members and I explored a variety of different improvisational scores until we arrived at SimulStart. SimulStart is a perceptual score that is part of choreographer and dance theorist Nina Martin's Ensemble Thinking dance system (Buckwalter). In SimulStart, two or more people attempt to move and stop simultaneously. Our exploration opened with short, minute movements, and, eventually, we moved to longer, more complex movement phrases. While, at first glance, SimulStart seems distant from the concepts of stillness, the performance of the work requires a neurological connection with another person, communication via silence, in order to eventually synchronize two unique neurological systems. In the iterations of this score, there are moments of pause and moments of movement, but the space between the dancers contains a palpable energy despite its inherent emptiness because of the dancers' intense focus on one another. This energetic focus fits perfectly within the working definition of nothingness (a predictable repetition that escapes its perceiver's conscious thought); hence, the score proved valuable enough to be included in the final iteration of the work.

The structure of the work also shifted several times in terms of the scores used, the sequence in which they were performed, and the duration of each section. The final choreography's four movements allude to the 
three movements allude to the three movements in Cage's 4'33"as a tribute to that which inspired the work. Each of the sections correlates to a particular aspect of my research. The first section enters through the lens of contextual stillness, the idea that stillness becomes perceived when something frames it, in a score in which the dancers (and a few extras) move vigorously about an audience whose eyes are closed. The closing of the eyes permits the body to more closely attend to its own stillness in contrast to the movement around it, a juxtaposition intended to heighten the experience of stillness in the audience member.

The second section of the work flips the previous script and allows the audience to move about the nominally still dancers. In this section, the dancers refrain from movement as much as possible while the audience is free to move around them at their leisure. This section seeks to embody the idea of silence $\sim$ stillness $\sim$ nothingness as negation, though it holds remnants of the previous score since a contrast between audience and dancer in terms of movement persists (in the previous score, the audience was stationary with moving dancers; in this score, the roles simply reverse, maintaining an inverted form of the previous relationship). Moreover, an experience of the contrasting states of the self as an audience member (still to moving) and of the dancers (moving to still) provides the audience the opportunity to peer into different parts of the mirror of nothingness (from the analogy employed earlier).

The third section utilizes the SimulStart score in a way I have never seen performed before; it engages the audience with the score as each dancer chooses an audience member at random to dance with. This section aligns closely with the Abramovic, Gann, and Lyotard conception of silence that alludes to the transcendence into an expanded consciousness via nothingness. The dancers use SimulStart to mimic the movements of an audience member-not only moving and stopping when the chosen member does so, but matching the volume and energy of the movement/stop as well. In performance, the space of nothingness between the pair performing SimulStart rests between audience and performer as the dancer forms a neurological connection with the unsuspecting audience member through space, filling the space between them with the palpable energetic focus mentioned in which the audience member senses a logic in the relationship between dancer and audience, though they may not be able to define it.

Finally, the last section plays with the definition for silence stillness nothingness that I arrived at: a predictable repetition that escapes its perceiver's conscious thought. The dancers in my work and I crafted a phrase together that is able to be performed en croix, meaning it moves in four perpendicular directions. The circular pathway of the movement means it does not travel in space as the dancers roll, swing their legs, and slide repeatedly for the duration of 24 minutes, slowly showing signs of exhaustion. The concept of this section derives from Margulis's research on the brain's perception of repetition eventually settling into silence. Human repetition cannot be perfect; however, I am curious as to whether or not the mind will detect the nuanced difference, the declining energy in the dancers or the continuity of pattern.

In terms of connotative value, the perceptions of the audience will be influenced by past experience and their own ideas of how they can fruitfully engage with the performance. While Stillness in Four Movements frames the experience within the bounds of its metaphysical mirror, nothingness ultimately "transpose[s] the performance onto the audience members," as Gann notes, an observation that states my research in the area most clearly. Further research in this area of inquiry promises to contribute to the dance field both on a theoretical and performance level. 


\section{WORKS CITED}

Abramovic, Marina. Interview with Sam Keller. "Artist Talk: Marina Abramovic in Conversation with Sam Keller." Fondation Beyeler (2014). Web. 5 Jul 2016.

Abramovic, Marina. "Marina Abramovic on art, performance, time and nothingness." Intelligence Squared (2014). Web. 1 Jul 2016.

Buckwalter, Melinda. Composing While Dancing. Madison Wisconsin: The University of Wisconsin Press, 2010.

Gann, Kyle. No Such Thing as Silence: John Cage's 4'33". New Haven, US: Yale University Press, 2010. ProQuest ebrary. Web. 12 September 2016.

Jensen, J. Vernon. “Communicative Functions of Silence.” ETC: A Review of General Semantics 30.3 (1973): 249-57. Web. 13 Jul 2016.

Jordania, Joseph. "Times to Fight and Times to Relax: Singing and Humming at the Beginnings of Human Evolutionary History." Kadmosmi \#1 (2009): 272-277. Web. 12 Jul 2016.

Kosoi, Natalie. “Nothingness Made Visible: The Case of Rothko's Paintings.” Art Journal 64.2 (2005): 20-31. Web. 15 Jul 2016.

Lyotard, Jean-Francois. “The Sublime and the Avant Garde.” Paragraph 6 (1985): 1-18. Web.

Margulis, Elizabeth Hellmuth. "Silences in Music Are Musical Not Silent: An Exploratory Study of Context Effects on the Experience of Musical Pauses." Music Perception: An Interdisciplinary Journal 24.5 (2007): 485-506. Web.

Rottner, Nadja. "The Imagistic Theatre of Robert Whitman." Modern Drama 58.1 (2015): 66-93. International Bibliography of Theatre \& Dance with Full Text. Web. 8 Sept. 2016. 